\title{
Rahvalaul «Naise tegemine»
}

\section{Felix Oinas}

Eestis on «Naise tegemine» ülemaaliselt tuntud. Esitame siin selle tüüpilise teisendi Vändrast aastaist 1878-79.

Teiste meestel kõikel naesed, pole mul vaesel mehel naista! Võtsin vana kase paku, tegin naese, vaesekese. Tõiste naestel kõikel pääd, pole mu naesel mitte pääd, võtsin vana kapsapää, tegin vaesel naesel pää. pole mu vaese naesel silmi, tegin naese vaesel silmad... pole mu naese vaesel suud, võtsin kirve tegin suu... pole mu naese vaesel kässa, võtsin kaksi kase puud... pole mu naese vaesel nisa, võtsin kaksi küpse kaali... pole mu naese vaesel kõhtu, võtsin vana püksi tükki... Tule ruttu, lähme lattu, lähme laudile magama!

See naljalaul algab üldiselt sissejuhatusega, milles, nagu näitelauluski, mees kurdab, et tal pole naist ja peab naise tegema.

Sissejuhatus algab vahel ka järgmiselt: Lätsi mõtsa kõndima, leidse üte tõrva kannu..., te'i säält [sellest] endäl naisukese. (Rõngu). Viru rannas ja paiguti Lõuna-Eestis esinevad «tõrva kännu» asemel «mädand känd», «kase pakk» ja «uhmri pakk». Mõnikord järgneb metsas kõndimine ka eelmisele sissejuhatusele.

Märgime järgnevas naise puuduvad kehaosad (õieti polegi tal mitte kui midagi) ja ainesed, millega nad Eestis asendatakse:

pea: kapsapää

kael: vana kitse kael

silmad: kassi, lamba, ruuna, tsirgu, siili silmad

nina: kaevu koogu konks

kõrvad: seened

kõht: väike pada, vana heinatutt, lehma, karu, hülge magu või kõht

rind: kaalikad, naerid, nirgi nisad, kase käsnad

jalad, reied: ruuna reied, voki jalad

käed: koera, kärbi käpad, karu käed

häbe: vana siili riist, varsa vitt

«Naise tegemise» lõpp rõhutab valdavas enamikus naise sarnasust nüüd teiste naistega: Siis sai naine kui muudgi naised (Jõhvi), Perast sai naine nigu muugi (Otepää) jne. Eeltoodud näitelaulus järgneb sellele veel naise magama kutsumine. Kose teisend lõpeb naise ebarahvapärase ülistusega. Osal lauludel puudub eriline lõpp. 
Soome «Naise tegemise» laulust on käepärast kõik trükitud materjalid. Toome siin soome vanima teisendi, kirja pandud Gottlundi poolt Juvalt a 1815-16.

Oli ju teiste naisel (?)

ei ju mul olnudki.

Mina võtsin kapsa kärä, tegin pää mu naisele, kapsa käre püha pää on ju minu naisel.

Oligi teiste naistel nina... mina võtsin kuuse käbi... Oligi teiste naisel silmad... mina võtsin kassi munnid...
Oligi teiste naisel käed... mina võtsin rohelised pajud... Oligi teiste naisel kõht... mina võtsin vana mütsi... Oligi teiste naisel jalad... mina võtsin sirged kased... Oligi teiste naisel häbed... mina võtsin tõrva kirnu...

Gottlundi teksti algridades on toimunud segadus. Esimene värss on defektne. Teises esinev partikkel pä (kasutatud naise puudumise rõhutamiseks) on tõlgendatud noomeniks pä̈̈, mis naisel puudub, ja laul jätkub seejärel selle asendamisega.

Soome tekstid loendavad ainult osa naise kehaosadest, mis vajavad tegemist resp. asendamist. Äratab tähelepanu, et nina esineb peaaegu kõigis teisendeis, rohkesti ka rinnad. Teistest kehaosadest on mainitud ainult 2-3. Seetõttu on laulud lühikesed.

Esitame nimekirja naisel puuduvaist kehaosadest ja ainestest, millega nad asendatakse:

pea: tõrvatünn, kapsa kärä

nina: lõngakera, kuuse käbi

hambad: räime vardad

juuksed: hobuse harjased

silmad: kassi, sea silmad, kassi munnid

rinnad: oina kotid, kase kännät

kõht: vana müts

jalad: sirged kased, adrakured

käed: kase oksad, rohelised pajud

häbe: tõrva kirn

Mõnes «Naise tegemise» teisendis on mainitud esemed, mis ei kuulu kehaosade hulka, nagu peegel, müts ja kingad. Nende esitamine on põhjustatud segunemisest naise riietamislauluga, osalt sobiva riimsõna taotlusest.

Osas soome lauludes esineb refrään, mis kordab ja kinnitab uue kehaosa tegemist, nt

Nii, nii edasi,

lõngakera, uus nina

oli minu eidel.

Või:

Nii, nii edasi,

tõrvaleili, uus peegel

oli minu eidel. 
Ja nii jätkuvad need mõninga varieerimisega kõigi kehaosade või muu kohta.

Taani «Naise tegemise» laulust oli kasutada 2 varianti. Üks neist on järgmine:

Teiste naistel on sä̈̈red, minu naisel ei midagi, nii võtsin paar veskikivi ja tegin naisele kaunid sääred.

Bom pirum ja bom pirum. Teiste naistel on jalad... nii võtsin paar sarapuu pähklit...

Teiste naistel on tagupooled... nii võtsin paar vasika puusa...
Teistel naistel on rinnad.... nii võtsin paar sea kintsu... Teistel naistel on nisad.... nii võtsin paar kirikutorni пuppu...

Teistel naistel on lõuad... nii võtsin paar kiviksest veski hammasrattast... Teistel naistel on ninad... nii võtsin paar seapõit. Bom birum ja bom birum.

Taani teine lühike lauluteisend kinnitab, et naisel ei olnud põlvi (asendamiseks ostis paar vehmri kinnituskonksu), häbet (asendamiseks ostis nahkhiire), kõhtu (asendamiseks ostis paar vukssaagi) ega nisasid (asendamiseks paar kirikutorni nuppu).

Laulus on vukssaed kõhu asenduseks kohatud, aga nende tarvituse on määranud riim (Rammesave - Mave). Sama on toimunud ka teistes värssides.

Sel teisendil esineb refrään ainult esimese salmi lõpul: «Kui sa ei soovi, tantsin veidi neidudega.»

Siin on nimekiri kehaosadest ja nende asendus-aineist:

nina: seapõied

lõuad: kivikesed veski hammasrattast

kõht: vukssaed

jalad: sarapuu-pähklid

põlved: vehmri kinnituskonksud

tagupool: vasika puusad

sääred: veskikivid

rinnad: sea kintsud

nisad: kirikutorni nupud, hõbenööbid

häbe: nahkhiir.

$$
* * * * * * * * * * * * * *
$$

«Naise tegemine» on korduslaul. Selle jälgede otsimine viib meid tagasi nekrutilaulule, tuntud, nagu nägime, kogu Euroopas. Sellest laulust - välja arvatud eesti ja soome versioonid - on kirjutanud üksikasjalise uurimuse Erich Seemann, «Das Lied vom «Bruder Melcher»»" (Zbornik za narodni Zhivot i obichaje, 40, 1962, 427-441). 
Seemann on näidanud, et nekrutilaul on rännanud Saksamaalt (võimalik, et seal loodud) Ungarisse ja Serbiasse. See jutustab noormehe sõjaväkke või sõtta minekust ja tema varustamisest. Noormehel pole mitte kui midagi - ei hobust, relvi ega isegi riideid, aga ta saab need oma kallimalt või emalt. Esitame järgnevas serbia laulu:

Ja nad [noormehed] läksid sõjaväkke, aga mu kallim jäi maha, see on, miks ta jäi maha: tal ei olnud ratsut. Aga ma hüppasin jalule ja sain talle mära.

Siin, kallim, on ratsu! tal ei olnud husaarikuube... ja sain talle vaiba... tal ei olnud läkiläkit... ja sain talle mesipuu... tal ei olnud mõôka... ja sain talle nüri noa... Siis läksin üles kingule ja vaatasin kingult alla, kelle kallim on kõige parem? Minu kallim on kõige parem: Ratsu tal komistas, vaip tal lipendas, mesipuu tal kõlkus. See on türklaste onnetus!

Türklaste mainimine laulu lõpul viitab Türgi pealetungidele ja osalistele vallutustele Lõuna-Euroopas 14.-16. sajandil.

Laulu kronoloogia suhtes on ka oluline, et selle vanim dateeritud käsikiri pärineb Saksamaalt aastast 1610. Selle veel varasem käsikiri leidus juba a 1555-59 Taani kuningakojas.

Sellest laulust on rohkesti eri tüüpe. Nekruti kõrval esineb euroopa laulus poiss, kes harrastab ratsutamist lihtsalt lõbu pärast. Teda tuleb varustada hobuse, päitsete, sadula, kannuste ja riietega. Mõnes versioonis ratsutab poiss pruudi juurde ja see küsib talt pulmariideid. Rootsis peab kuningas Orre ratsutama pidusöögile ja vajab selleks riideid. Inglismaal soovib ratsutaja saada hobust, päitseid, sadulat ja kannuseid. Kui ema need talle muretseb, kihutab ta pulli seljas kui raju minema. Ungaris puuduvad mehel vahel mitte ainult hobune, vaid ka söök, suitsud ja võimalus tantsida. Saksa laulus ei ole Susannal hobusekronu ega magamiseks voodit, aga need muretsetakse.

Millistes ringides lauldi seda laulu? Selle kohta pole Seemanni järgi palju andmeid. Laulu leidumine ühes sõdurite laulikus näitab, et seda kasutati sõdurilauluna. Seda lauldi ka käsitöösellide, majateenijate, talutüdrukute, sulaste ja õmblejannade hulgas. Eriti populaarne oli see laste uinutamislauluna. Töölised laulsid seda töölt tulles. Samuti lauldi seda nimepäeva ja vastlapäeva pühitsemisel ja pandi lunastamisel. Seda harrastati ka ettekandelauluna, kusjuures eeslaulja laulis seda salmide kaupa, mida juuresolijad kordasid.

$$
* * * * * * * * * * * * * *
$$

Laulu eesti ja soome versioonid kuuluvad lähedalt kokku, ühelt poolt eriti põhjaranniku ja kagu-eesti ja teiselt poolt kagu-soome ja ingeri kirjapanekud. Võrreldagu nt pea: eesti (laialt) kapsapää soome Juva kaali (kapsa) kärä; rind: Jõhvi kase käsnad Impilahti koivun (kase) kännät; silmad: Jõhvi kassi silmad Venjoki (ingeri) kissan (kassi) silmät; kõrvad: Räpina katsi kõivulehte Juva kaksi lehtilöistä jt. 
Taani versioonis pole ühtegi detaili, mil oleks eesti või soome vaste, välja arvatud asjaolu, et taani lauludel on, nagu soome omadelgi, refrään.

Võib esialgselt oletada, et «Naise tegemine» on sündinud Taanis, läinud Rootsi (kus see tänapäeval kadunud), edasi Soome ja kandunud lõpuks Kagu-Soome ning Ingeri kaudu Eesti põhjarannikule, kust see on levinud üle kogu maa.

«Naise tegemine» on ülimalt groteskne, ühendades inimliku teema detailidega looma- ja taimeriigist ning eluta loodusest. Oma sarkastilisuses taotleb see naise mõnitamist kõigi võimalike vahenditega. Sellest mõned näited. Eesti laulus tehakse naine mädand kännust, tema pea kapsapääst, kõht lehma maost, silmad lamba silmadest, hambad vanast saetükist jne. Sama alandavad on teistegi rahvaste asendusesemed. Soomes asendab pead tõrvatünn, kõhtu vana müts, rindu oina kotid jne. Ja ometi nimetatakse neid kehaosi sarkastiliselt pühadeks! Taanis omakorda pannakse naisele rindadeks sea kintsud ja tagupooleks vasika puusad.

Laul üritab naise arvel vallatut nalja teha. Ei või unustada, et homo sapiens'i võimalik «sünonüüm» on homo ridens, kes nõuab ka oma osa. Ja on ürginimlik näha naeruväärsust kõige tõsisemaiski asjades, nagu Ain Kaalep nii veenvalt on näidanud («Maavallast ja maailmakirjandusest», 1984, lk 279).

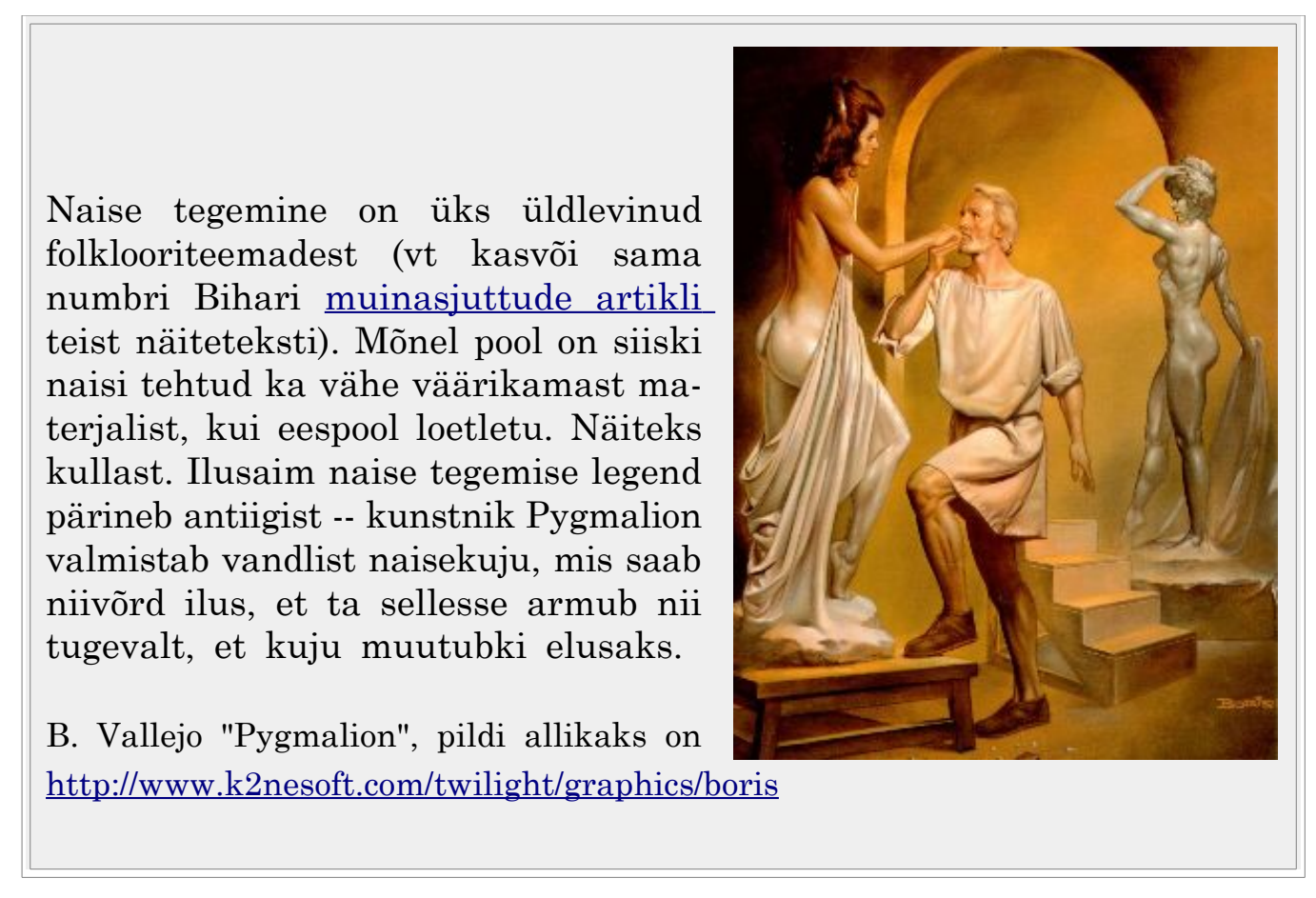

Vaatleme lõpuks «Naise tegemise» vahekorda teiste eesti korduslauludega. Korduslaule on käsitlenud Oskar Kallas oma väitekirjas «Die Wiederholungslieder der estnischen Volkspoesie» (Helsinki, 1901). Laulus «Härjad murtud» jutustatakse, kuidas poiss laskis loomad louna ajal laane alla. Tuli hunt ja murdis musta ning kirju härja. Poiss nuttes koju. Vastu tulid vanemad ja küsisid, mis viga. Poiss kordas juhtunud õnnestust täpselt samade sõnadega, nagu see laulu algul oli esitatud. Seepeale trööstisid teda vanemad, et ärgu ta nutku, sest lehmad kodus poegivad ja toovad asemele uued.

Sama struktuur on ka teistel korduslauludel, milles poisil või tüdrukul on juhtunud õnnetus ja vanemad neid trööstivad. Sama laulutüüp esineb meie naabreist ainult leedulastel. 
«Naise tegemise» struktuur on eelmisest oluliselt erinev. Sissejuhatusele järgnev 4-realine salm kõneleb naisel puuduvast peast ja selle asendamisest kapsapääga. Kõik järgnevad salmid kordavad seda sõna-sõnalt, erinev on ainult naise puuduv kehaosa ja selle asenduse nimetus. See meil ebatavaline laulutüüp läheb tagasi euroopa nekruti sõttamineku laulule ja selle järglastele.

Materjali saatmise eest avaldan tõsist tänu järgmistele teadlastele: prof. Isidor Levin, Ellen Liiv, Senni Timonen, Astrid Tuisk ja prof. Ülo Valk. 